\title{
ÔRNL/NUUREG/TTM-İ̄o
}

\section{Critical Heat Flux Experimentation in an Annular Test Section}

\author{
J. D. White \\ A. E. Levin
}

Prepared for the U.S. Nuclear Regulatory Commission Office of Nuclear Regulatory Research

Under Interagency Agreements DOE 40-551-75 and 40-552-75 
Contract No. W-7405-eng-26

Engineering Technology Division

CRITICAL HEAT FLUX EXPERIMENTATION IN AN ANNULAR TEST SECTION

J. D. White

A. E. Levin

Manuscript Completed - March 7, 1978

Date Published - March $19 / 0$

NOTICE: This document contains information of a preliminary nature. It is subject to revision or correction and therefore does not renresent a final report.

\author{
Prepared for the \\ U.S. Nuclear Regulatory Commission \\ Office of Nuclear Regulatory Research \\ Under Interagency Agreements DOE 40-551-75 and 40-552.-75
}

\author{
Prepared by the \\ OAK RIDGE NATIONAL LABORATORY \\ Oak Ridge, Tennessee 37830 \\ operated by \\ UNION CARBIDE CORPORATION \\ for the \\ DEPARTMENT OF ENERGY
}

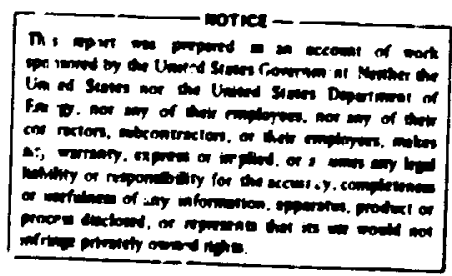




\section{CONTENTS}

$\underline{\text { Page }}$

KEYWORDS $\ldots \ldots \ldots \ldots \ldots \ldots \ldots \ldots \ldots \ldots \ldots \ldots \ldots \ldots \ldots \ldots \ldots \ldots \ldots \ldots$ v



1. INTRODUCTION $\ldots \ldots \ldots \ldots \ldots \ldots \ldots \ldots \ldots \ldots \ldots \ldots \ldots \ldots \ldots \ldots \ldots$

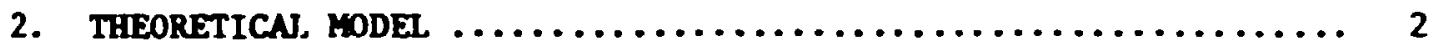

3. EXPERTMENTAL EQUIPYENT AND PROCEDURES $\ldots \ldots \ldots \ldots \ldots \ldots \ldots \ldots \ldots, 4$

3.1 Test Facility $\ldots \ldots \ldots \ldots \ldots \ldots \ldots \ldots \ldots \ldots \ldots \ldots \ldots \ldots$

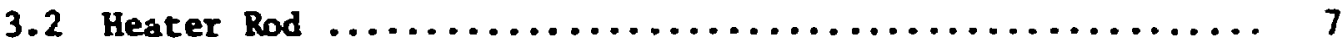

3.3 Experimental Procedures $\ldots \ldots \ldots \ldots \ldots \ldots \ldots \ldots \ldots \ldots \ldots . \ldots \ldots$

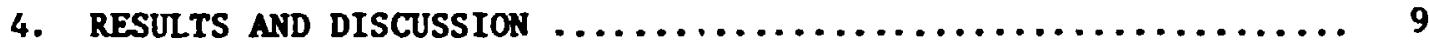

4.1 Experimental Results ....................... 9

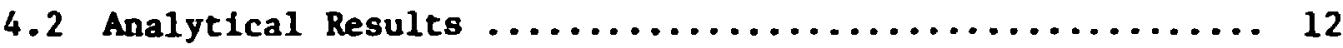

4.3 Discussion of Experimental and Analytical Results ...... 21

4.3.1 Steady-State Tests ................... 21

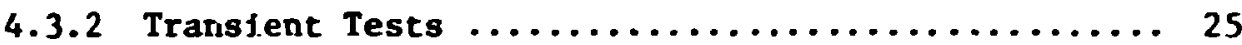

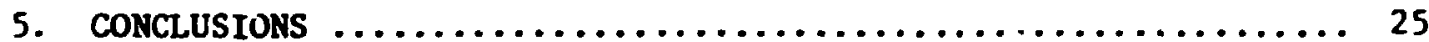

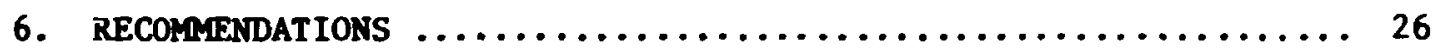

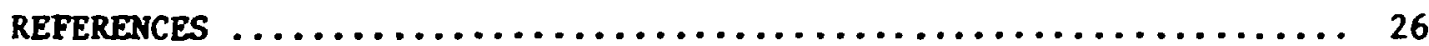




\section{KEYWORDS}

Pressurized-water reactor, blowdown heat trarsfer, Forced Convection Test Facility, electrical fuel pin simulators, critical heat flux (CyF), defarture frow nucleate boiling (DNB), annular geometry, dryout, MacBethBarnett, stepped cosine power profile, transient critical heat flux, 3.66-m (12-ft) heated length. 


\title{
CRITICAL HEAT FLUX EXPERMMERTATION \\ IN AN ANNULAR TEST SECTIGN
}

\author{
J. D. White \\ A. E. Levin
}

\section{ABSTRACI}

Steady-state critical heat flux experiments have been performed in the Forced Convection Test Facility (FCTF), an annular test section contalning a single electrically heated rod, for the purpose of testing the applicability of existing critical heat flux correlations. Good accuracy has been obtained using the HacBeth-Barnett critical heat flux correlation for annuli, cnrrected for the "stepped cosine" power profile of the heater.

The equivalent diameter of the test section, based on the wetted perineter, is $2.1 \mathrm{~cm}(0.83 \mathrm{in.})$; the heated-to-wettedperineter ratio is 0.252 . The heated length of the heater rod $18366 \mathrm{~cm}$ (144 in.).

Woninal pressures for the teste have ranged from 7.2 to $15.5 \mathrm{mN} / \mathrm{m}^{2}$ (1044 to $2250 \mathrm{psia}$ ); coolant flow rates have been $0.32 \mathrm{dm}^{3} / \mathrm{sec}(5 \mathrm{gpm}), 0.63 \mathrm{dm}^{3} / \mathrm{sec}(10 \mathrm{gpm})$, and $1.26 \mathrm{dm}^{3} / \mathrm{sec}$ (20 $\mathrm{gpm}$ ); and heater powers of $72 \mathrm{~kJ}, 122 \mathrm{~kW}$, and $144 \mathrm{~kW}$ have been used. Maximus error in prediction of first observed critical heat flux is 21\%; rus error is $11.7 \%$.

Attempts have also been made to predict the occurrence of critical heac flux during blowdowns (depressurization transients) of the FCTF. The results of these predicttons are inconclusive at this time.

\section{INTRODUCTION}

Sir:gle nuclear fuel pin simulators are tested in the Forced Convection Test Facility (FCTF). These simulators are electrical heaters with heated lengths of $366 \mathrm{~cm}(144 \mathrm{in.})$ and diameters of $1.07 \mathrm{~cm}(0.422 \mathrm{ln}$. and are similar to some pressurized water reactor fuel pins.

The operation of the FCTF is 1imited, in steady state, by the temperacure at the surface of the heater rod used as a nuclear fuel pin sinulator. The most desirable heat transftr regimes are forced convection and nucleate bolling in order to keep the heater surface temperature 10w. In the realm of nucleate bolling, the potential exists to blanket the rod with vapor by bolling so violently that liquid cannot. reach the rod. This is referred to as departire from nucleate bolling (DNB). In regions of large vold fractions, evaporation of the film of 1 lquid cove ing 
BLANK PAGE

$\because$ 
the rod is possible, causing the phenomenor known as dryout. The heat flux rejuired to cause these phenowina is called critical heat flux (CHF), and this condition 18 indicated by a sharp rise in the surface temperature of the rod as the heat transfer coefficient drops by as much as three orders of magnitude.

In oróer to study the conditions under which CHF occurs in steady state in the FCTF, a series of experiments has been run at various pressures, flow rates, and powers. Several CHF correlations were exanined; the MacBeth-Barnete CHF correjation for annull has been found to prejict with good accuracy the occurrence of CHF in steady-state tests in the FCIF when corrected for the nonunifors heat flux profile of the heacer In use.

This report outlines the tests that have been conducted and presents a comparison between predicted and observed results.

One other area, only briefly explored, is the application of the steady-state CHF correlation to predict CHF in depressurization transients (blowdowns) of the FCTF. A short discussion of these results is included.

\section{THEORETICAL MODEL}

There does not $\epsilon$ Zist, at present, any completely theoretical mode1 '-o describe CHF. Most correlations, therefore, are wholly or partially expirical in nature. The MacBeth-Barnett correlation for annuli is completely empirical and 18 presented for steady-state uniform heat flux operation. This correlation was chosen due to its specific applicability to FCTF annular geometry. Since the heater rods used in the FCTF have a stepfed power profile approximating a chopped cosine (with an integrated power proftle sindlar to that found in nuclear reactors), the ef fect of this nonuniform heat flux distribution must be considered. This has been done using a "local conditions" hypothesis, namely, that CHF occurs at a point of constant thermodynanic equilibrfum enthalpy, irrespective of the rod power profile. 
The MacBeth-Barnet: correlation is presented in Collier as

$$
\frac{q_{c r}^{e c}(z)}{10^{6}}=\frac{A\left(h_{f_{g}} / 649\right)+B\left(\Delta h_{s u b}\right)_{1}}{C+z},
$$

where

$$
\begin{aligned}
h_{f g} & =\text { latent heat of vaporization }\left(B t u / 1 b_{m}\right), \\
\left(\Delta h_{s u b}\right)_{1} & =\text { inlet subcooling of the coolant }\left(B t u / 1 b_{m}\right), \\
z & =\text { axial position on the heater (In.), }
\end{aligned}
$$

and

$$
\begin{aligned}
A= & 67.45 D_{h}^{0.68}\left(G \times 10^{-6}\right)^{0.192} \\
& \times\left[1-0.744 \exp (-6.512 D)\left(G \times 10^{-6}\right),\right. \\
B= & 0.25787 D_{h}^{1.261}\left(G \times 10^{-6}\right)^{0.817}, \\
C= & 185.0 D_{e}^{1.415}\left(G \times 10^{-6}\right)^{0.212},
\end{aligned}
$$

where, for an annulus of Inner diamecer $D_{i}$ and outer diameter $D_{0}$,

$$
\begin{aligned}
& D_{e}=D_{0}-D_{1}(\text { In. }), \\
& D_{h}=\left(D_{0}^{2}-D_{1}^{2}\right) / D_{1}\left(1 n_{.}\right),
\end{aligned}
$$

and $G=$ mass velocity $\left(1 b_{m} / h r \mathrm{ft}^{2}\right)$.

Since the nonuniform heat flux coriection involves thermodynamic equilibrium enthalpy, the enthalpy at any point in the fluid along the rod must be calculated. ${ }^{2}$ Thus

$$
h(z)-h_{f, \text { sat }}=\frac{4 q_{\max }^{\prime \prime}}{G D} \int_{0}^{z} f(z) d z-\left(\Delta h_{\text {sub }}\right)_{i} \text {, }
$$

where

$$
f(z)=q^{\prime \prime}(z) / q_{\max }^{\prime \prime} .
$$


If the MacBeth-Barnett correlation is put into the fore

$$
\left.q_{c r}^{\prime \prime}(z)=X-\operatorname{YDG}\left[h(z)-h_{f, 8 a t}\right) / 4\right],
$$

then, by substituting (7) into (9) and transforning back to the original form (1),

$$
\frac{q_{\text {aax }, c r}^{-c}(z)}{10^{6}}=\frac{A\left(h_{f g} / 649\right)+B\left(\Delta h_{g u b}\right)_{1}}{C f(z)+\int_{0}^{z} f(z) d z} .
$$

This can be further simplified to

$$
q_{\max , c r}^{c o}(z)=q_{c r, u}^{e r} \frac{c+z}{c f(z)+\int_{0}^{z} f(z) d z},
$$

where $q_{c r, u}^{e n}$ is the uniform heat flux CHF predicted by (1).

The tern $q_{\max , c r}(z)$ is the value of the peak heat flux required for CHF to occur at point $z$ on a rod with the specified heat flux profile $f(2)$. Dividing $q_{\max , c r}^{-\infty}(2)$ by the actual rod maximum heat flux at a certafn power gives the ratio of the critical heat flux to the actual heat flux. This number is called the departure from nucleate bolling ratio (DNBR) and can be multiplied by the heat flux at a point $z$ to find the predicted critical heat flux at tha: point. ${ }^{3}$ A DNBR of unity predicts that a CHF condition will occur. This method of prediction was used during this series of tests. The results of the predictions are discussed in Part 4.

\section{EXPERIMENTAL EQUIPMENT AND PROCEDURES}

\subsection{Test Facility}

A11 steady-state CHF tests were carried out in the FCTF, a schematic of which is shown in Fig. 1. The annular test section has a hydraulic equivalent diameter of $2.10 \mathrm{~cm}(0.828 \mathrm{in}$.$) , and the heated-to-wetted-$ perimeter ratio is 0.252 . Coolant flows down a downcomer and up through 


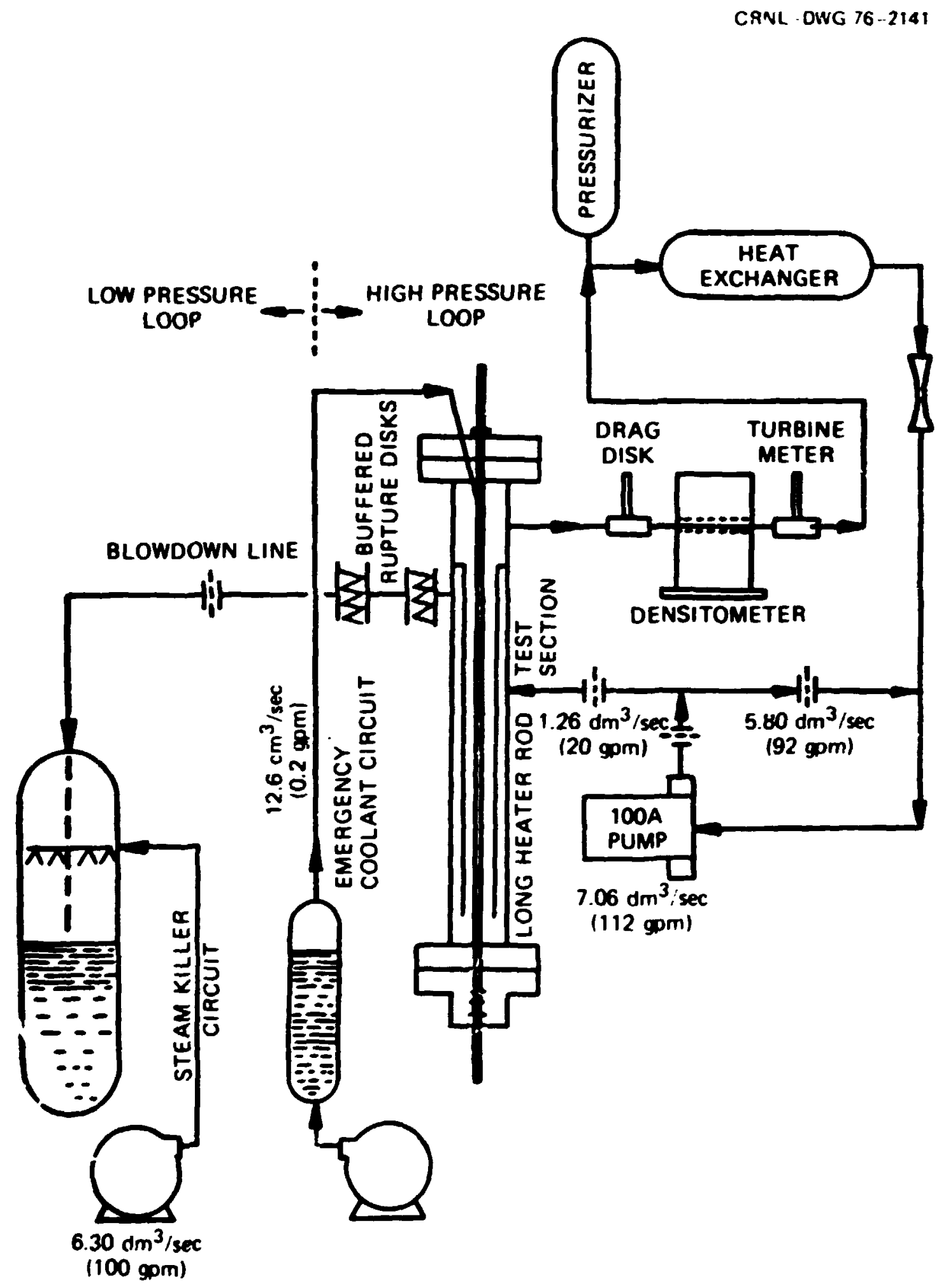

F1g. 1. Forced Convection Test Facility. 
the test section, exiting through a spool piece containing flow injtrumentation. The test section, a cross-sectional view of which is shown in Fig. 2, consists of a pressure vessel (containment), core barrel, and heater rod. The space between the contalnment and the core barrel forms the downcower. Only the heater rod is heated by power in this apparatus; the core barrel and containment are heated only by the fluid passing over then. There is, however, a guard heater outside the contaiment to hinder heat losses from the fluid in the downcomer.

OANL - DWG 74 - 10784 A

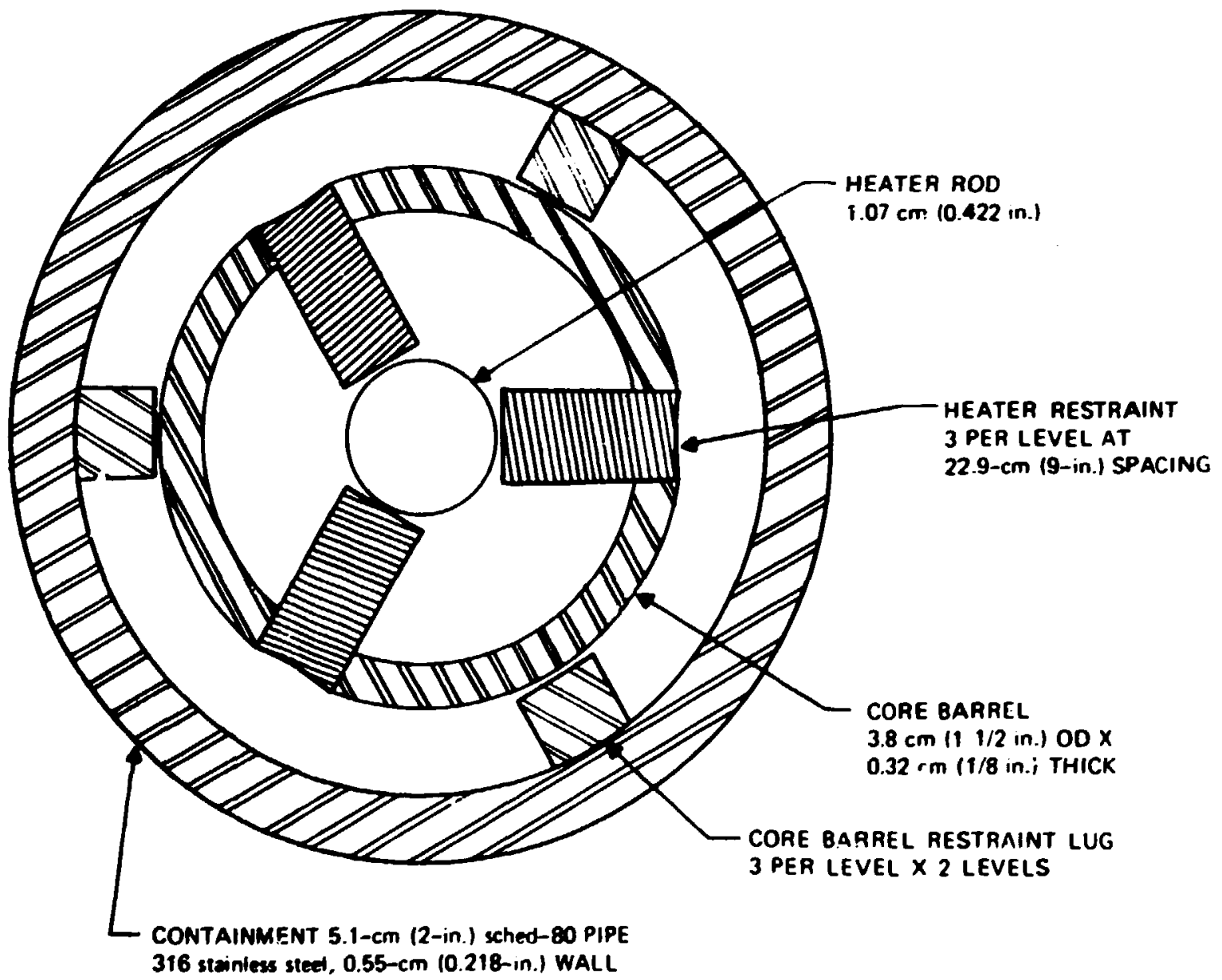

P1g. 2. PCTP test section cross-sectional view. 


\subsection{Heater Rod}

The heater used in the FCTF, a cross-sectioncl view of thich is seen in Fig. 3, is an electrically heated nuclear fuel pin simulator protuced by the Wat low Electric Yanufacturing Company of St. Louis, Missouri. A schematic of the rod, showing heater zone lengths, powers, and thermocouple locations, is shown in Fig. 4. The power profile of the rod is a "stepped cosine," designed to approximate the chopped cosine profile found in some nuclear reactors. The heater is instrumented with therwocouples spot-welded into grooves in the inner sheath of the heater and also with thermocouples placed in the central ceramic core of the heater. The sheath thermocouples are monitored during experiments for indications of CHF cinditions.

ORNL-DWG 75-12882R

HEATER ROD CROSS SECTION (0.42ć-in. DIAM)

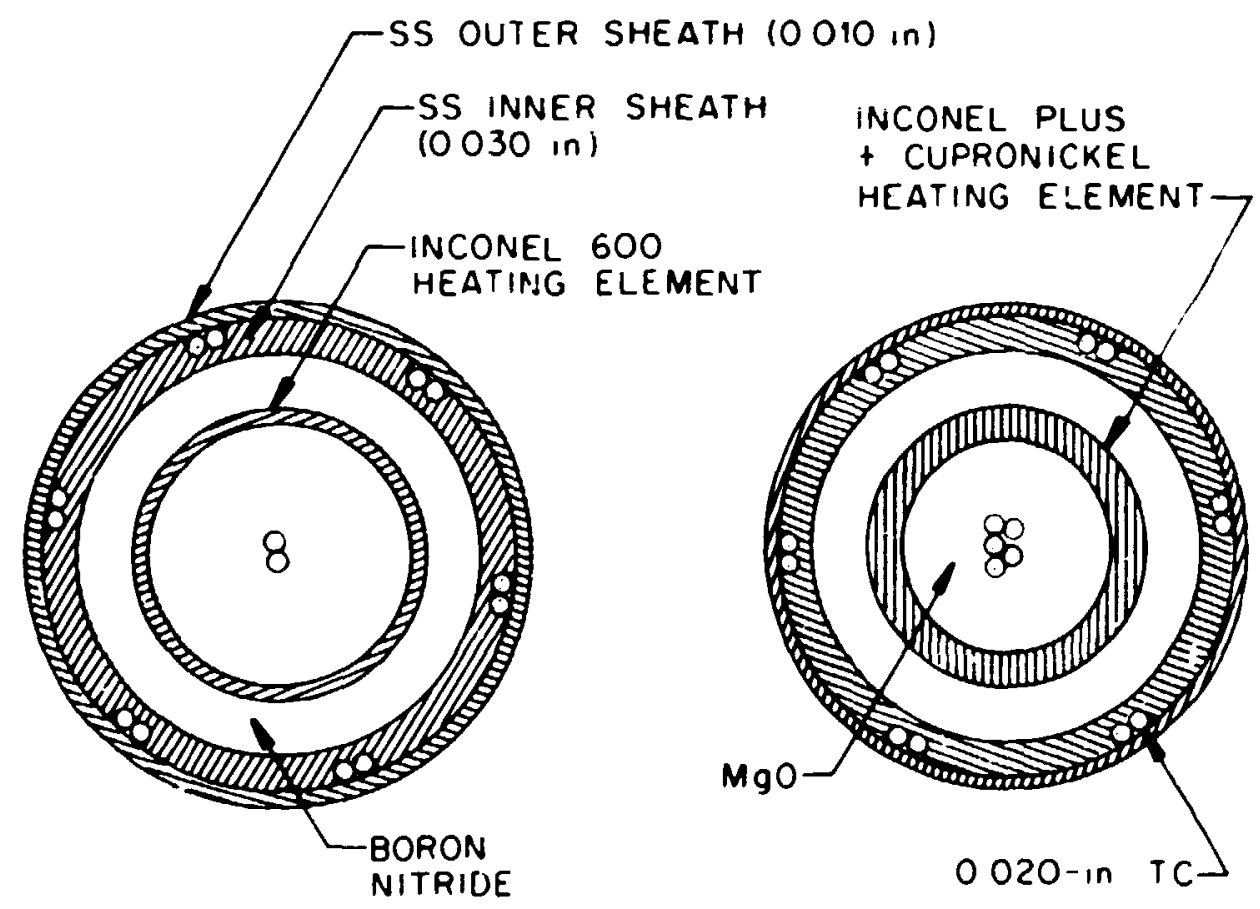

Fig. 3. Heater rod cross section. 


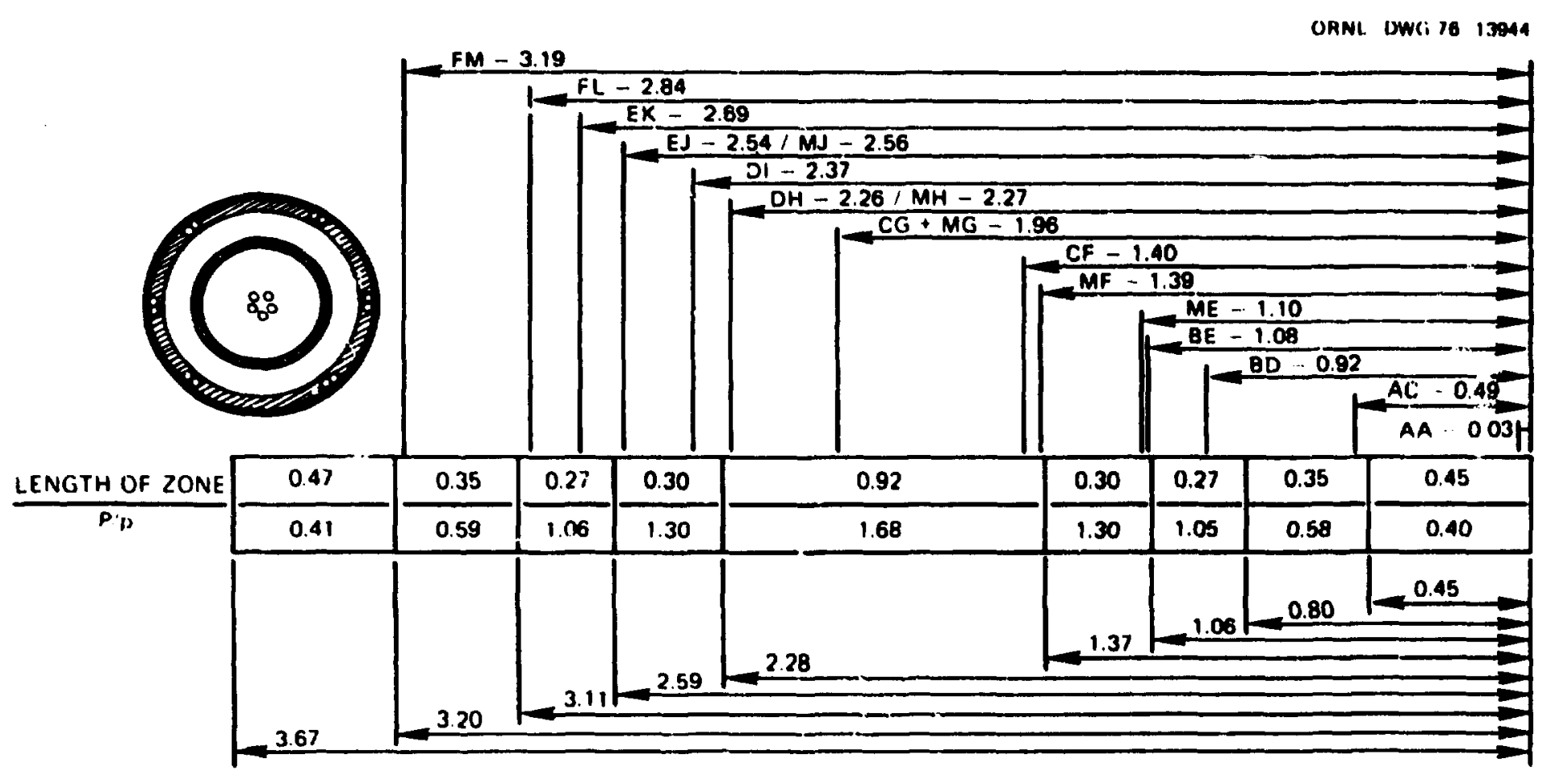

Fig. 4. Schematic of FCT $\vec{r}$ heater showing thermocouple locations and heat zone layouts. Dimensions in meters. 


\subsection{Experimental Procedures}

The MacBeth-Barnett equation contains five independent parameters that depend on efther the coolant conditions or the systen geometry. These are the only parameters that can be altered in order to change the critical heat flux prediction. These parameters are the mass velocity, latent heat of vaporization (related to system pressure), inlet subcooling (related to system pressure and coolant inlet temperature), and the equivalent diameters based on both heated and wetted perimeter. Since the last two parameters are fixed by the geometry of the test section, the testing procedure involved changing only two parameters - mass velocity and pressure. Gnce these two propertles were fixed for a test, the coolant inlet temperature was slowly increased unt 11 CHF was indicated by a sheath thermocouple. The sheath thermocouple can be used to indicate the occurrence of CHF because the immediate degradation of surface heat transfer capability accompanying CHF causes a rapid escalation in the surface and sheath temperatures and a corresponding rapid escalation in the thermocouple output. When the thermocouple output reached a preset level, it activated an overtemperature power trip set to prevent permanent camage to the rod.

During a test, data on flow rate, pressures, and temperatures were recorded on a Beckman ANSCAN data acquisition system and stored on magnetic tape. When processed, this information provides a continuous record of system conditions before, during, and after CHF. The coolant conditions at the point of first CHF provide input to the MacBeth-Barnett CHF correlation so that DNBR can be calculated where CHF occurred.

\section{RESULTS AND DISCUSSION}

\subsection{Experimental Results}

In order to adequately test the correlation, experiments were carried out over a wide range of pressures and flow rates. The nominal conditions for each test are listed in Table 1. The actual pressures at which the tests were performed varied somewhat from the nominal. The pressure varlance in experiments $76-6-1,76-7-1,76-7-2$, and $76-7-4$ was not more 
Table 1. Noninal conditions for steady-state CHF test

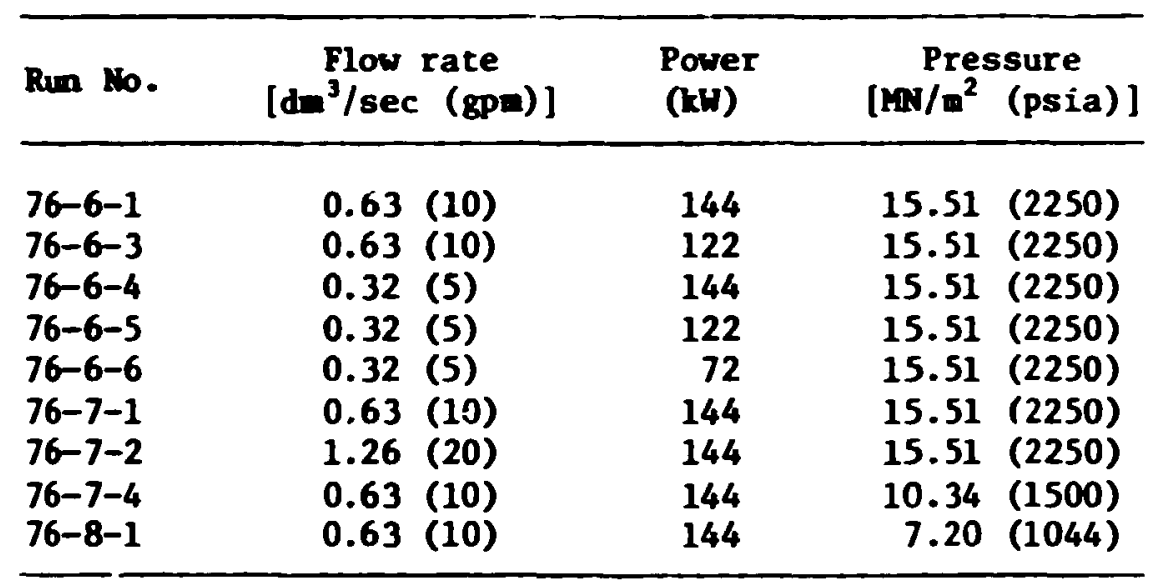

than $0.34 \mathrm{MN} / \mathrm{m}^{2}$ (50 psi) from the nominal value. In the other tests, however, the pressure was sonsiderably higher than nominal. This was due to the effect of bulk bolling in the test section. At flow rates of $0.32 \mathrm{dm}^{3} / \mathrm{sec}(5 \mathrm{gpm})$, coolant velocity $1 \mathrm{~s}$ about $0.45 \mathrm{~m} / \mathrm{sec}(1.5 \mathrm{fps})$. Flow bolling at such a low flow rate tended to override the effect of the pressurizer in the system, causing the system pressure to rise. The same behavior was observed at low inlet subcoolings, where bolling occurred through the entire test section. For example, in test 76-6-6, the inlet temperature was taken to saturation before CHF occurred at a thermocouple level protected by an overtemperature power trip. This caused bulk bol1Ing throughout the entire test section, causing the pressure to rise to $17.7 \mathrm{mN} / \mathrm{m}^{2}$ (2570 psia).

The results of the tests, including predictions of DNBR, are 1isted In Table 2. Although it is not immediately apparent from the table, these tests showed a high degree of reproducibility. Tests 76-6-1 and 76-7-1 were run at the same flow rate and about the same pressure. The incidence of CHP 18 seen at about the same inlet temperature, and the same thermocouple exhibits first CHP, with subsequent rewet. More thermocouples showed CHP In test $76-7-1$ due to the fact that the overtemperature trip polnt was set at a higher level, allowing the power to remain on longer.

Although none of the other tests are duplicated in the table, two experinents vere actually run at the same conditions for each test The 
Table 2. Results of CHF tests

\begin{tabular}{|c|c|c|c|c|}
\hline Run No. & $\begin{array}{c}\text { Core barrel } \\
\text { inlet } \\
\text { temperature } \\
\text { at CHF } \\
{\left[\mathrm{K}\left({ }^{\circ} \mathrm{F}\right)\right]}\end{array}$ & $\begin{array}{c}\text { Test section } \\
\text { inlet pressure } \\
\text { at CHF } \\
{\left[\mathrm{MN} / \mathrm{m}^{2} \quad(\mathrm{psia})\right]}\end{array}$ & $\begin{array}{l}\text { Thermocouple(s) } \\
\text { on which CHF } \\
\text { was observed }\end{array}$ & $\begin{array}{l}\text { Predicted DABR } \\
\text { at point of CHF }\end{array}$ \\
\hline $76-6-1^{a}$ & $600(621)$ & $15.46(2243)$ & $\begin{array}{l}\mathrm{DH}^{b} \\
\mathrm{DI}\end{array}$ & $\begin{array}{l}7.985 \\
1.15\end{array}$ \\
\hline $76-6-3$ & $611(640)$ & $15.94 \quad(2313)$ & $\begin{array}{l}\mathrm{DH} \\
\mathrm{DI}^{b} \\
\mathrm{EJ} \\
\mathrm{EK}\end{array}$ & $\begin{array}{l}0.93 \\
1.07 \\
1.036 \\
1.121\end{array}$ \\
\hline $76-6-4$ & $575(575)$ & $16.51 \quad(2395)$ & $\begin{array}{l}\mathrm{DH}_{b} \\
\mathrm{DI}^{2}\end{array}$ & $\begin{array}{l}0.914 \\
1.044\end{array}$ \\
\hline $76-6-5$ & $594(610)$ & $16.28(2361)$ & $\begin{array}{l}\text { DI } \\
\text { EJ } \\
\text { EK } \\
\text { FL }\end{array}$ & $\begin{array}{l}1.12 \\
1.075 \\
1.164 \\
1.125\end{array}$ \\
\hline $76-6-6^{c}$ & $628(671)$ & $17.72(2570)$ & $\mathrm{DI}^{b}$ & 0.967 \\
\hline $76-7-1^{a}$ & $598 \quad(517)$ & $15.59(2262)$ & $\begin{array}{l}\mathrm{DH}^{b} \\
\mathrm{DI} \\
\mathrm{EJ}\end{array}$ & $\begin{array}{l}1.035 \\
1.19 \\
1.15\end{array}$ \\
\hline $76-7-2$ & $614(646)$ & $15.81 \quad(2294)$ & $\begin{array}{l}\text { DHb } \\
\text { DI } \\
\text { EJ } \\
\text { EK }\end{array}$ & $\begin{array}{l}0.89 \\
1.033 \\
0.997 \\
1.087\end{array}$ \\
\hline $76-7-4$ & $583 \quad(590)$ & $10.50 \quad(1523)$ & $\begin{array}{l}\mathrm{EK}_{b}^{b} \\
\mathrm{FL}^{b} \\
\mathrm{FM}\end{array}$ & $\begin{array}{l}1.207 \\
1.177 \\
1.45\end{array}$ \\
\hline $76-8-1^{d}$ & & \multicolumn{3}{|c|}{ None } \\
\hline \multicolumn{5}{|c|}{  } \\
\hline
\end{tabular}


fIrst was used to show when CHF could be expected, thus indicating when the ANSCAN sustem should be activated, since a limited anount of data can be processed. In each case, the first and second runs showed c'ose agreement; however, only the run for which the ANSCAN operated is listed In Table 2. Plots of sheath thermocusple temperature vs time are sinown In Pigs. 5-8. The tine scales are arranged so that the first occurrence of caf falls approximately at zero secords. The graphs were drawn by a Calcomp ploteer from information taken from the ANSCAN system. The plots are developed from data points taken every tenth of a second.

As can be seen in the plots, the onset of CHF is readily apparent due to the rapid rise in the sheath temperatures that imodiately follows the departure from nucleate boiling or dryout. The features of these plots will be discussed in wore detall in the following section.

\subsection{Analytical Results}

The results of predictions using posttest results are presented in Table 2 and Fig. 9. Posttest calculations were necessary due to the variance of the system conditions from the nominal. The maximum error at first CHF is 20.7\% through 76-7-4, and the rms error for all tests through 76-7-4 is 11.77. Run 76-8-1 is not included in these calculatfons because no CHF occurred. The predicted DNBR, as noted, is 1.09 at the 229-cm (90-in.) level. Since CHF did not occur, the error cannot be evaluated but is assumed to be less than 9.2\%. The error at first occurrence of CHF is emphasized nere, and the reasons will be explained in the following section.

Predictions were also made, assuming nominal conditions, for three flow rates $\left[0.32,0.63\right.$, and $1.26 \mathrm{dm}^{3} / \mathrm{sec}(5,10$, and $\left.20 \mathrm{gPm})\right]$ over a range of pressures from saturation at $561 \mathrm{~K}\left(550^{\circ} \mathrm{F}\right)$ coolant inlet temperature to $15.51 \mathrm{mN} / \mathrm{m}^{2}(2250 \mathrm{psia})$ at the same temperature and over a range of coolant Inlet temeratures from $561 \mathrm{R}\left(550^{\circ} \mathrm{F}\right)$ to saturation temperature $\left[618 \mathrm{R}\left(652.9^{\circ} \mathrm{F}\right)\right]$ at $15.51 \mathrm{MN} / \mathrm{m}^{2}(2250 \mathrm{psia})$. Results of some of these predictions are presented in Figs. 10-12.

Predictions of DiBR at $0.63 \mathrm{dm}^{3} / \mathrm{sec}(10 \mathrm{gpm}), 561 \mathrm{~K}\left(550^{\circ} \mathrm{F}\right)$, and $15.51 \mathrm{~m} / \mathrm{m}^{2}$ (2850 psia) were also made using the $W-3, B \& W-2$, and Janssen- 


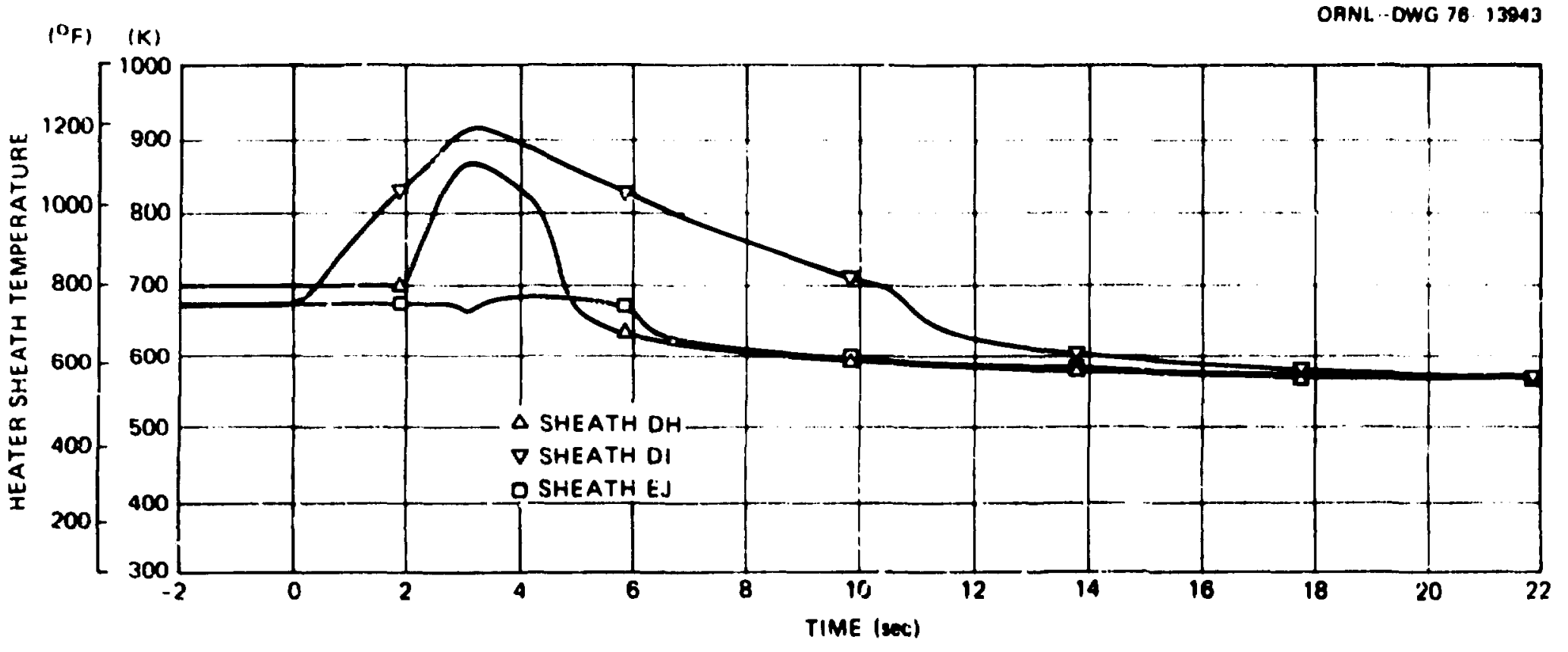

F1g. 5. Heater sheath thermocouple outputs during experiment 76-6-4. 


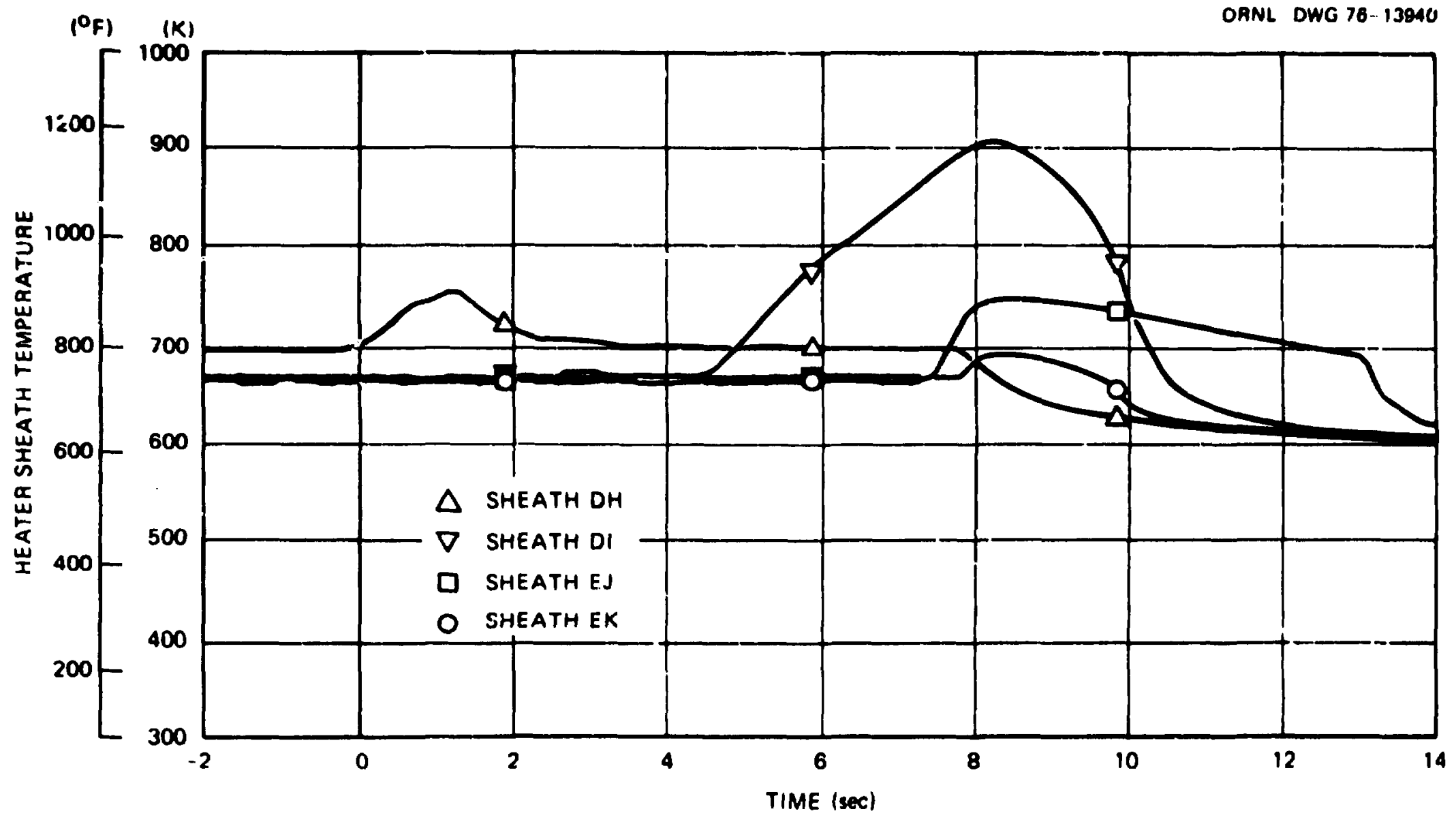

F18. 6. Heater sheath thermocouple outputs during experiment 76-7-1. 


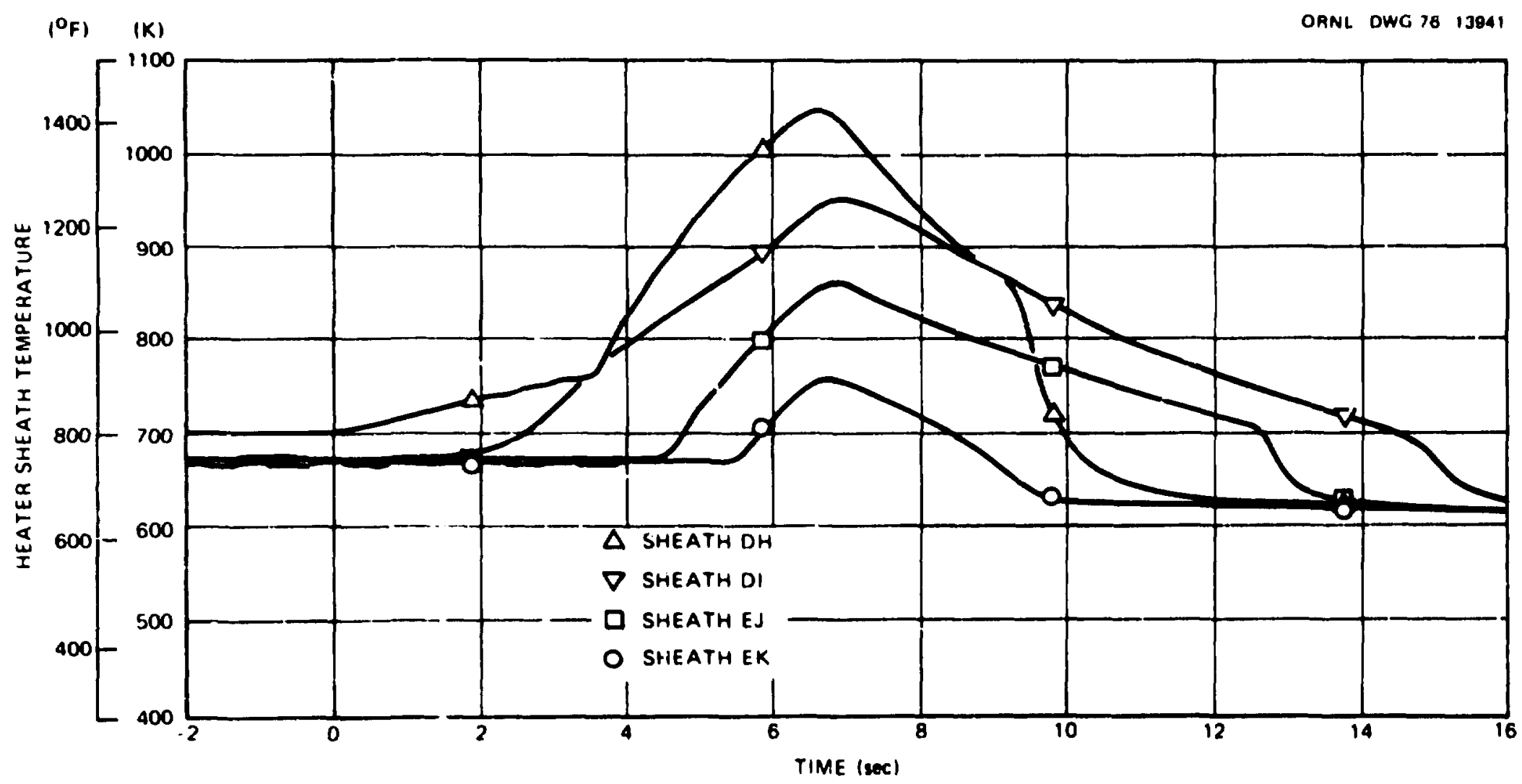

F1g. 7. Heater sheath thermocouple outputs during experiment 76-?-2. 


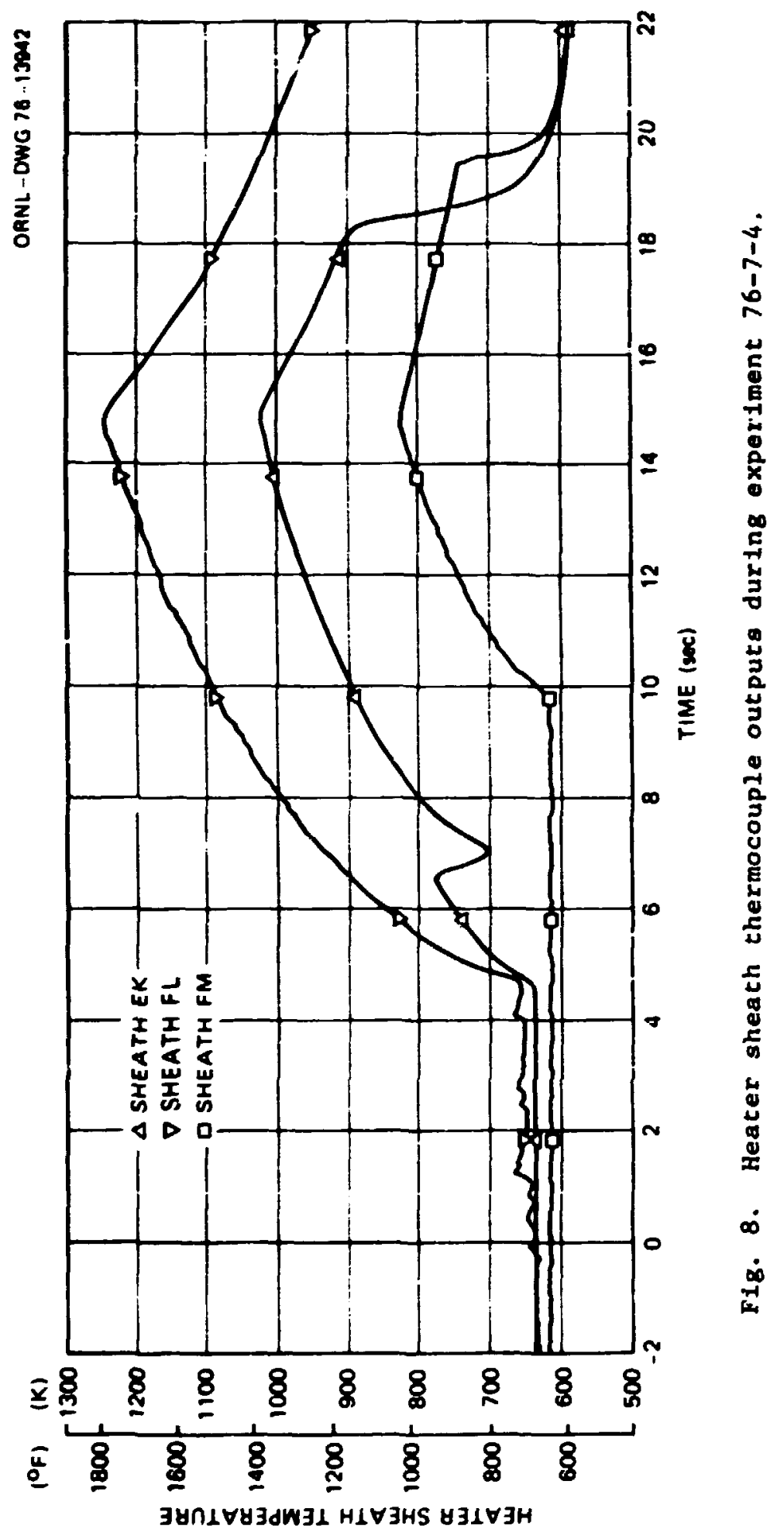




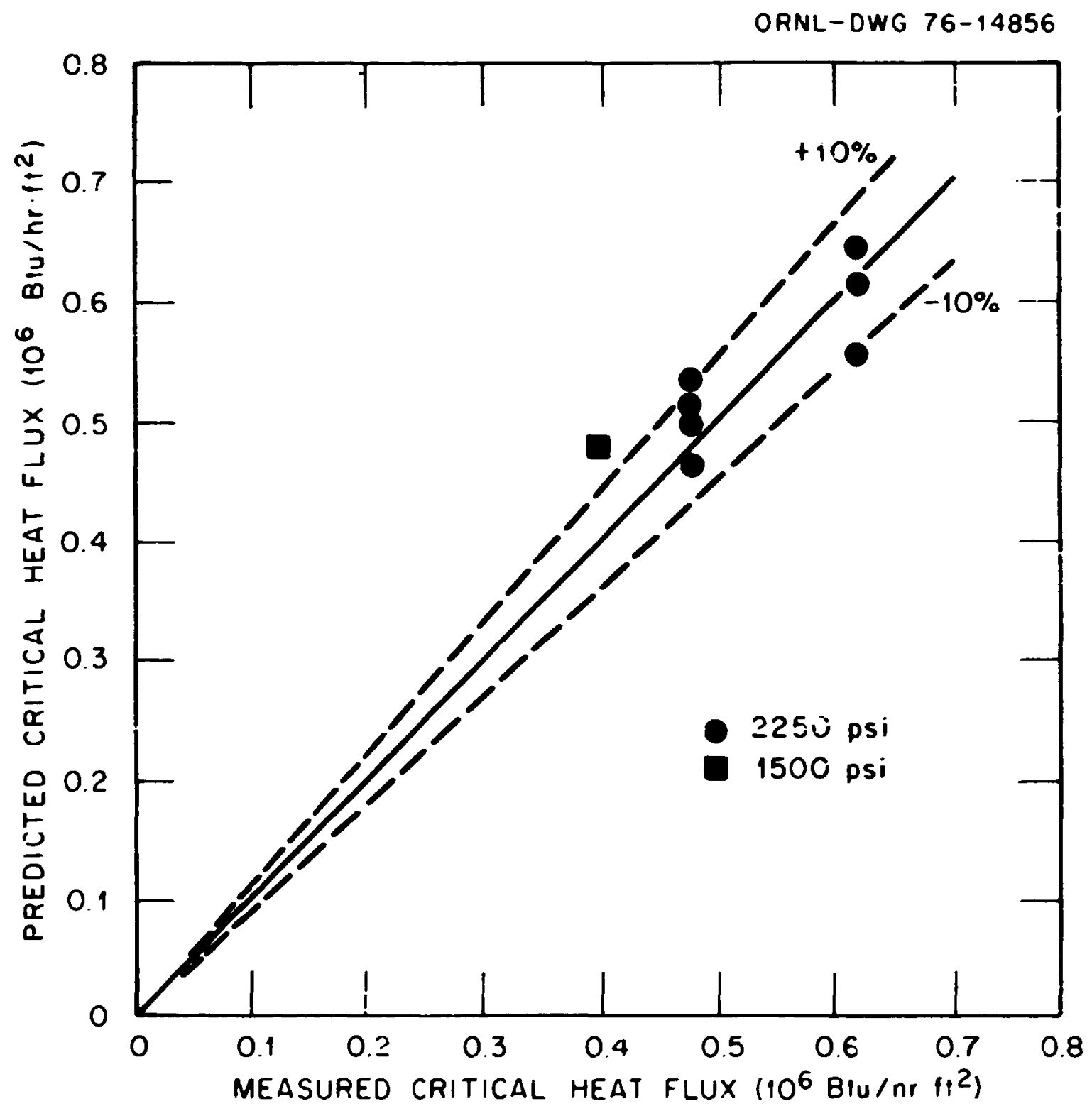

Fig. 9. Steady-state CHF results for the single-rod annular flow geometry compared with the predictions of the MacBeth-Barnett correlation for annuli. 


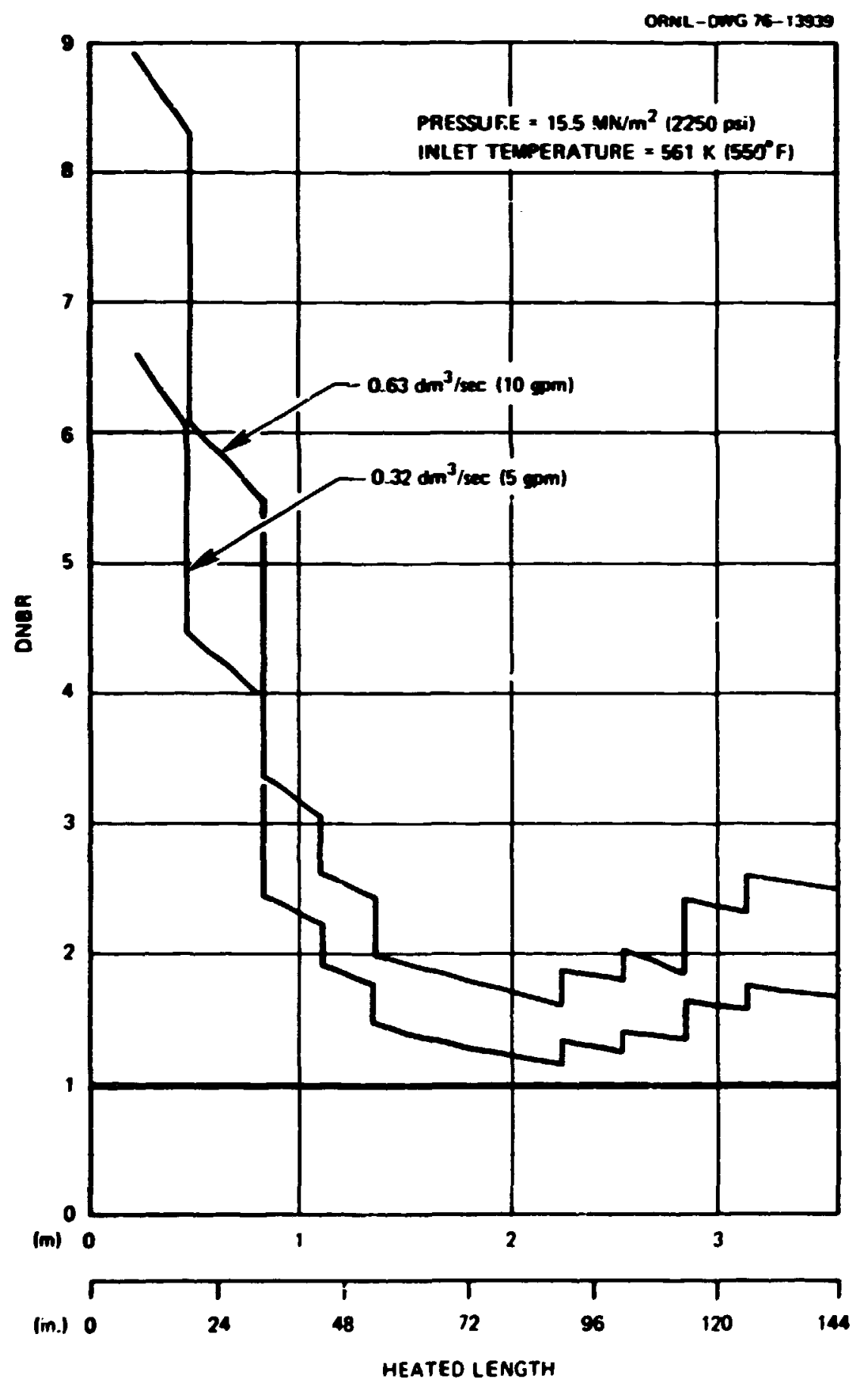

F1g. 10. DABR calculated by MacBeth-Barnett correlation for FCTF for different flow rates. 


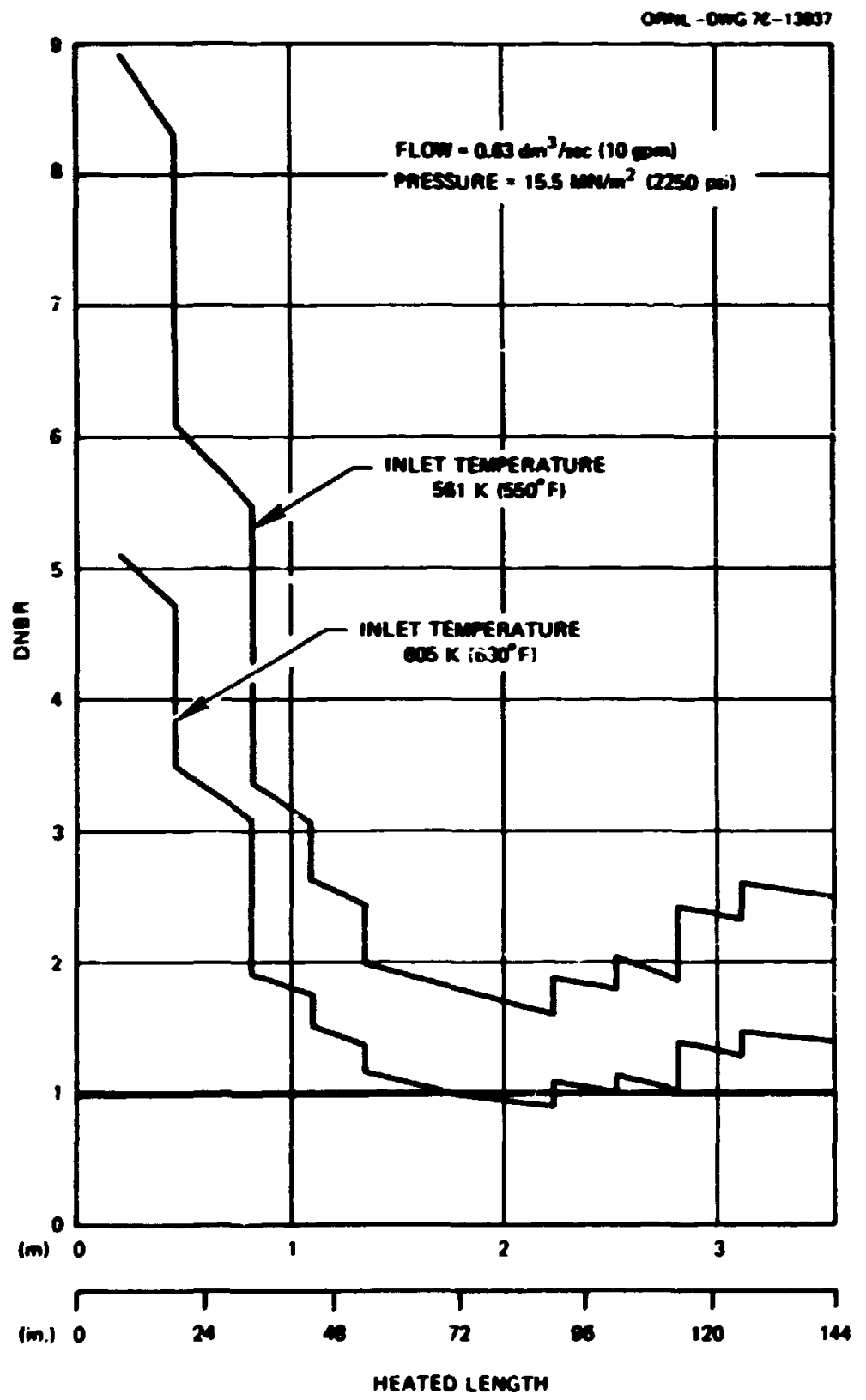

Fig. 11. DNBR calculated oy MacBeth-Barnett annulus correlation for FCTF for different inlet temperatures. 


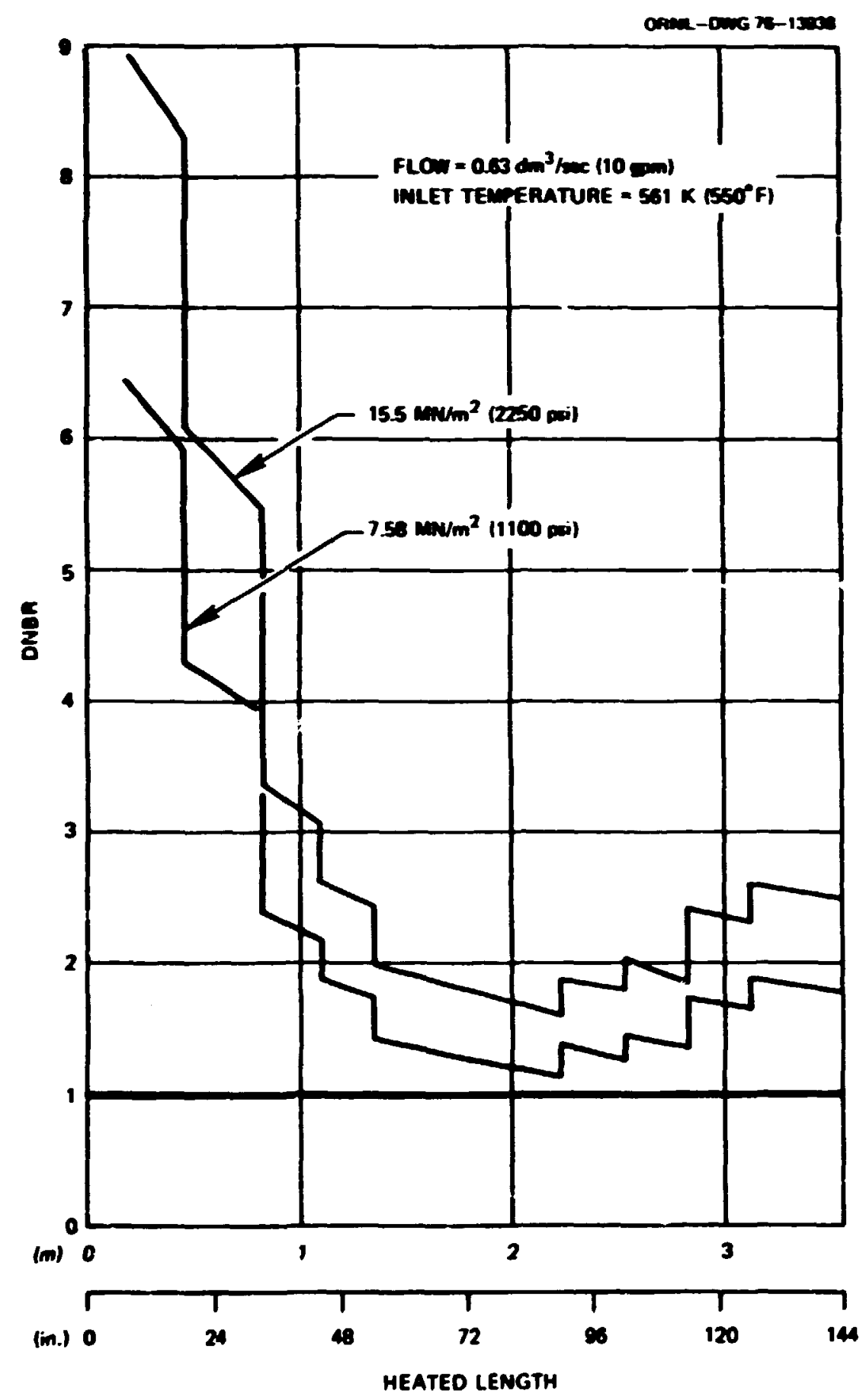

F18. 12. DNBR calculated by MacBeth-Barnett annulus correlation for PCTF for different pressures. 
Levy CHF correlations. These represent normal steady-state operating conditions for FCTF. One or wore system parameters is outside the suggested range of each correlation. The predictions are presented in Table 3, for the sake of comparison, along with the prediction from the MacBeth-Barnett correlation. All predictions are those at the 229-ca (90-in.) level, the point at which minfman DAB is predicted by the MacBeth-Barnett correlation.

Table 3. Predictions of DiBR at 229-cn (90-in.) level

\begin{tabular}{lc}
\hline \multicolumn{1}{c}{ Correlation } & Predicted DiBR \\
\hline W-3 & 0.83 \\
B\&W-2 & 0.93 \\
Janssen-Levy & 0.44 \\
MacBeth-Barnett (annulus) & 1.60 \\
\hline
\end{tabular}

\subsection{Discussion of Experimental and Analytical Results}

\subsubsection{Steady-state tests}

The temperature-time curves presented in Sect. 4.1 give a very good representation of the phenomenon of critical heat flux and suggest some of the causes. In experiment 76-6-4, presented in Fig. 5, only two thermocouples exhibited CHF. The temperature of thermocouple DH, located In the highest power zone, climbs at a rate of $188 \mathrm{~K}\left(338^{\circ} \mathrm{F}\right)$ per second, clearly fllustrating the drastic reduction in surface heat transfer coefficient. Also of some interest is the behavior of thermocouple EJ. The temperature begins to fall, then rises slightly, only to quench about $2.5 \mathrm{sec}$ later. The fintial drop in temperature is due to the loss of power, due to thermocouple DI reaching the overtemperature trip level. When rod power is shut off, volds in the coolant immediately collapse. This, in curn, causes a drop in pressure; when saturation pressure is reached, some boflligg may occur. There remains some stored energy in 
the heater, and it is probably this stored energy combined with the pores-trip-related pressure drop that causes the heater to go into CHF at this level. This incident would seen to indicate, too, that conditions causing Cur verge on a wetastable fluid state and that any slight stimuius can cause CHP to occur.

Test 76-7-1, shown in Fig. 6, exhibited one other characteristic sometimes seen in CHF experiments: that of rewetting of the surface. Th1s occ:urs when the vapor film that has bullt up around the heater surface suddenly collapses, allowing liquid =o reach the surface, hence the tern "rewet." This rewetting of the rod 18 followed $4.5 \mathrm{sec}$ later by CBF indicated by therwocouple DI. Coolant conditions did not change appreciably in the tine span 0 to $5 \mathrm{sec}$, Indicating once again that the coolant is in a metastable condition, needing only the slightest stimulus to cause CHF. The CHF condition spreads from DI to thermocouple EJ abcut $3 \mathrm{sec}$ later. Thermocouple EK also exhibits what appears to be CHF; however, this happened $z$ fter the power trip, which occurred at $7.6 \mathrm{sec}$. This behavior is the same sort that was seen on EJ in run 76-6-4 and is very likely due to the same effect.

Experiment 76-7-2, a plot for which is shown in Fig. 7, shows the same basic behavior that has been seen in previous tests. There is, however, one feature unique to this run, that being the temperature trace of $\mathrm{DH}$. Although the temperature at that level begins to rise at zero seconds, the rate of increase 18 only abjut $17 \mathrm{~K}\left(31^{\circ} \mathrm{F}\right)$ per second, as compared with the $115 \mathrm{~K}\left(207^{\circ} \mathrm{F}\right)$ per second 1ncrease several seconds later. This effect has not been observed on any other run, and the reason for the slow coast-up has not yet beer determined. One possible explanation, howeve:, is that CHF occurred at a point very close to $\mathrm{DH}$, possibly on a part of the surface at the same level but at an azimuthal location 1.57 radians $\left(180^{\circ}\right)$ from the thertwcouple. A gradual spreading of the departure from nucleate bolling could account for the thermocouple's behavior.

The final experiment shown, 76-7-4, in Fig. 8, also has several unique characteristics. The first is the behavior of thermocouple FL. It should be noted that this test was carried out at about $10.34 \mathrm{mN} / \mathrm{m}^{2}$ (1500 psia). If the MacBeth-Barnett correlation 18 examined, it will be 
seen that, for all conditions fixed except pressure, the critical heat flux Increases as pressure deireases, since $h_{f_{g}}$ increases with lower pressure. This bohavior was exhibited in this test, since the inlet temperature had to be taken almost to saturation before CHF occurred, as compared with runs 76-6-1 and 76-7-1, where the lalet subcooling was substantial at CHF. The mechanisa for CHF here is very likely dryout, and it is possible that the erratic behavior of FL fron 0 to $4.5 \mathrm{sec}$ is due to the unstable behavior of the thin Iiquid film fresent on the rod inodiately preceding dryout. Another possible explanation for this behavior is that the flow regime was that of slug flow, and the erratic behavior could be due to alternate slugs of vapor and liquid passing by the rod surface at this level, causing entrance into caf followed by a rapid rewet. Also of note is the rewetting of the rod at thermocouple Ex, followed by a return to CHF. Again, this is Jue most likely to instabilities in the coolant and could possibly be a result of entrained liquid droplets striking the heater surface at that point. CHF conditions occurred only in the upper regions of the rod and spread gradually upward to the $M$ level, indicating a dryout of the liquid film at the end of the rod.

The geometry of the test section also has an effect on the CHF behavior of the rod. The most important geometric effect is probably that due to the rod centering screws, which are placed at $22.9-\mathrm{cm}(9-\mathrm{in}$.) intervals along the rod (see Fig. 2). The screws can possibly act as turbulence inducers in the lower quality zegions, providing better flow mixing than expected. There are centering screws in the close proximity of both the $H$ and $K$ levels of the rod, and their presence may account in part for the rewetting seen on thermocouples DH and EK in runs 76-7-1 and 76-7-4 respectively. In areas of annular flow, these screws can possibly act to disrupt the liquid film at the heater surface and could account for dryout CHF occurring earlier than predicted.

As shown in Table 2, the accuracy with which first CHF is predicted is very good at $15.51 \mathrm{mN} / \mathrm{m}^{2}$ (2250 psia), but the accuracy decreases somewhat at lower pressure. The prediction at first CHF is stressed, due to the effect that CHF has upon rod surface conditions. When CHF occurs, the heater surface temperature rises rapidly, as has been seen previously. This rise in temperature can spread by conduction to other levels of the 
rod, causing increased nucleation and an entry into CHF sooner than the correlation would predict. This "spreading" of the CAF, for example, way te responsible for the occurrence of critical heat flux at thermocouple PI in test 76-7-4, though the predicted DABR was 1.45 .

One other explanation exists for the discrepancies in predicted vo actuel DiBR (assuning that CHF occurs at a DABR of 1.0), having to do wth the "local conditions" assumption ade in the nonuniform beat flux correction tern. The local conditions hypothesis, as mentloned previcusly, assunes that CAP occurs at a certain thernodynanic equilibriun enthalpy (or quality), regardless of the heater power profile. Use of this assumpt1on, therefore, does not take into account any "flow wewory," that is, the transport of stean along the test section and the resultant alteratlons of slip ratios, vold fractions, and flow regines. The flow memory effect would not be nuch of a factor in low-quality flows, and, in fact, the correlation does a better job of prediction at higher inlet subcooling. In the low-quality zone in the test section, the average power is somewhat less than that of the entire rod, whereas the correction factor is close to unity. This would cause too low a DNBR to be predicted. This has been indicated in analytical calculations by the fact that predicted DNBR has been 1 ess than unity at the $F$ and $G$ levels of the rod, wth no occurrence of CHF. In the high-quality zone, however, the neglecting of any flow memory effects would tend to cause the predicted DNBR to te too high, as has been seen in Table 2.

The inlet temperature used for predictions was not the coolant temperature at the entrance to the downcomer but rather the temperature at the bottom of the downcomer (the "core barrel" inlet). The dectsion to use this temperature was made because local fluid conditions within the test section were better represented by using the temperature at the beginning of the heater. Although this was not a large factor at the higher flow rates, the temperature rise in the downcomer was significant In the 0.32- $\mathrm{dm}^{3} / \mathrm{sec}(5-\mathrm{gpm})$ tests, especially in run 76-6-4. The heating of the water In the domcomer is partially due to losses by the water in the core, and these losses may also be partly responsible for inaccuracies in the ansiytical calculations. 


\subsubsection{Transient tests}

The FCTF is designed to test heater rods during blowdowns of the system. During these blowdowns, the time to $\mathrm{CHF}$ is measured, and data are taken in much the same way as in steady-state CHF tests. Atterpts have been made to predict DNBR at the point of CHF during transients using the steady-state correlation. Such attempts have wet with nixed success. Two such predictions have been made. One had an error of less than 10\%; the error in the second was wore than 80\%. This large inaccuracy is due largely to uncertainties in the flow in the test section during blowdown.

When blowdown occurs, flow imed lately reverses; thus the test section outlet becomes the "inlet" for the purposes of the correlation. Flow-measuring devices currently exist several feet downstream of the test section outlet, as shown in Fig. 1. The flow-measuring devices in the FCTF (turbine meter and drag disk) do not operate accurately in two-phase flow, which exists in the entire test sectici. during blowdown. Estimation of the flow rates in the test section is, therefore, difficult, and it is these uncertainties that are discussed. Attempts are currently under way to increase the reliability of these instruments in two-phase flow. If the instrumentation can be made more rellable, more accurate input to the correlation will then be available to test the accuracy of a steady-state correlation under transient conditions.

\section{CONCLUSIONS}

The riacBeth-Barnett critical heat flux correlation for annull does a good job of predicting steady-siate critical heat flux when corrected for the nonuniform heat flux profile of the FCTF heaters. Although Collier $11 \mathrm{sts}$ the range of the correlation as 4.2 to $9.7 \mathrm{MN} / \mathrm{m}^{2}$ (600 to 1400 pgia) and 61 to $274 \mathrm{~cm}$ (20 to $108 \mathrm{in.}$ ) heated length, ' this series of experiments indicates that the range can be extended to at least 15.9 $\mathrm{MN} / \mathrm{m}^{2}$ (2300 psia) and $366 \mathrm{~cm}$ (144 in.). The local conditions assumption for the nonuniform power correction works well in the low-quality region; however, in high-quality flows the effect of flow memory is belleved to cause the correction factor to be less accurate. Indications are that 
the steady-state CHF correlation may be used to predict the occurrence of critical heat flux in transients; however, more data must be examined before this point is clear.

\section{RECOMTERDATIONS}

Further work should te conducted in orjer to more thoroughly test the applicability of the MacBeth-Barnfte correlation. A new test section, wth a swaller hydraulic diameter and ne centering screws, is currently urder construction. Steady-state CHF tests and blowdowns should be conducted in the new facilicy as before, with the analytical predictions continuing.

Further work on correcting the MacBeth-Barnett correlation for nonuniform heat flux should also be done. Such corrections as the Tong "F" factor and the B\&W "F" factor should be evaluated.

Finally, more work should be done to improve the accuracy of twophase flow measurements. Flow-measuring devices should be installed at the test section inlet to obtain better mass flow rate information, especially during blowdowns. These steps are essential to obtaining and testing predictions of transient CHF.

\section{REFERENCES}

1. J. G. Collier, Convecive Boiling and Condensation, pp. 263-268, HcGraw-Hill, London, 1972.

2. L. S. Tong and J. Weisman, Thermal Analysis of Pressurized Water Reactors, pp. 203-207, American Nuclear Society, Washington, 1970.

3. R. H. Wilson et al., "Critical Heat Flux in a Nonuniformly Heated Rod Bundle," pp. 56-62 in Two-Phase Flsw and Heat Transfer in Rod Bundles, ed. by V. E. Schrock, Am. Soc. Mech. Eng., New York, 1969. 